\title{
The Practice Exploration of the Penetration of the Dragon Dance Option Course in Shanghai Higher Vocational Colleges
}

\author{
Kong Huangsheng ${ }^{1, a}$ \\ lassociate professor, master of physical education and training, Shanghai College of Agriculture and Forestry \\ ShangHai. China 201600. \\ a14719@shafc.edu.cn
}

\begin{abstract}
With the comprehensive promotion of the ideological and political construction of university courses, Shanghai Higher Vocational Colleges actively deepen the education and teaching reform, fully tap the ideological and political resources of various courses, give full play to the educational function of each course, and comprehensively improve the quality of personnel training. This study adopts the methods of literature review, case study, questionnaire survey and mathematical statistics to study the practice of moral education in Dragon Dance Course in Shanghai vocational colleges. The research shows that: 1 . Actively carrying out the ideological and political education of dragon dance elective course is conducive to improving the teaching effect of moral education and establishing students' national cultural confidence; 2. Both the experimental class and the control class think that it is the most effective way to infiltrate the moral education for the students to set up a good image of the physical education teachers; 3 . After the infiltration of moral education in higher vocational colleges, the cultivation of students' morality and self-cultivation does not rely entirely on the ideological and political theory course, which shows that other disciplines have more and more obvious influence on students' ideological cultivation.
\end{abstract}

Keywords: higher vocational colleges, Dragon Dance options class, Moral education

\section{INTRODUCTION}

Culture is the soul of a country and a nation[1]. Chinese excellent traditional culture is the spiritual lifeline of the Chinese nation, an important source of socialist core values, and a solid foundation for us to stand firm in the world culture. Higher vocational colleges should play the role of inheriting national excellent cultural media, and become the main battlefield to effectively popularize and carry forward national excellent traditional culture. Dragon dance is an important carrier of dragon culture communication. Dragon dance elective course teaching is not only to enhance students' physique, but also to cultivate students' national pride and national cultural confidence[4]. Building the "soul" of the nation and the "characteristics" of the campus are the original intention of the school to carry out the dragon dance. As college students in the new era, they should have national feelings and human care. The Central Committee of the Communist Party of China (CPC) emphasizes that
"Building Morality and cultivating people" is the foundation of a school[2], and the first thing to implement it is to carry out moral education. The infiltration of moral education in sports elective course is a part of the teaching reform of "Ideological and political course" in school physical education in the new era. The practical research on the infiltration of moral education in Dragon Dance elective course in Shanghai higher vocational colleges is in line with the development requirements of the new era, and is conducive to the cultivation of comprehensive talents with all-round development of morality, intelligence, sports, beauty and labor, as well as the inheritance and development of Chinese excellent traditional culture, Establish national "cultural confidence"[3]. Therefore, this study is of fundamental and unique significance for schools to implement the fundamental task of "cultivating morality and talents". 


\section{RESEARCH METHODS}

\section{1. literature method}

In order to better understand the research status of the infiltration of moral education in physical education curriculum in higher vocational colleges, this paper reviews the relevant data, including CNKI, superstar, etc., and sorts out and summarizes the relevant literature.

\section{2. interview method}

In order to obtain comprehensive and accurate research related information, the researchers communicated with the physical education teachers of Shanghai Urban Construction Vocational College, Shanghai Academy of Arts and crafts and Shanghai business college.

\section{3. questionnaire survey}

\section{(1) Design of questionnaire}

During the design of the questionnaire, a large number of materials about the infiltration of moral education in physical education teaching were consulted to ensure that the content and structure of the questionnaire were consistent with the problems of this paper, and the validity and reliability of the questionnaire were tested.

\section{(2) Questionnaire distribution and collection}

In April 2021, a questionnaire survey was conducted among the students of grade 2019 and grade 2020 of dragon dance elective course in Shanghai Vocational College of agriculture. 200 questionnaires were distributed, 196 were recovered, 195 were effective, and the effective recovery rate was $98 \%$.

\section{4. case analysis}

\section{(1) Experimental object}

Students of 2019 and 2020 dragon dance option courses in Shanghai Agricultural Vocational College are the research objects. 100 students in 4 dragon dance options classes in 2019 carry out normal physical education class teaching, and 100 students in four Dragon Dancing option classes in 2020 adopt the case teaching of curriculum ideological and political to carry out the infiltration moral education of dragon dance elective courses. The same teacher has classes at different times.

\section{(2) Experimental time}

March 1, 2021-april 23, 2021

\section{(3) Contents of the experiment}

In order to confirm the effect of the Dragon Dance option course in Shanghai Vocational College, 100 students of 2020 dragon dance option course in Shanghai Vocational College were studied as the experimental objects of infiltration moral education, and conducted two physical education courses a week and 16 physical education courses. The Dragon Dance option course uses "Ideological and political cases" and "micro class video" to arouse students' emotion and stimulate their interest in dragon dance; Inherit the traditional Chinese culture and establish the confidence of the national culture; Explore cooperative practice and innovate teaching of "curriculum ideological and political case"; The practice design should be carried out by condensing the spirit of anti epidemic and seeking the national spirit.

\section{(4) Purpose of experiment}

Through the pre and post test of experimental class and control class, the moral education of dance dragon option course is adopted to influence the experimental class. Through the questionnaire survey and analysis of the students in the experimental class and the control class, the teaching of the case of physical education and politics in vocational colleges is conducive to promoting the teaching effect of moral education penetration education.

\section{5. mathematical statistics}

This study deals with and analyzes the experimental results of experimental class and control class by using spss20.00 statistical software by Excel software and mathematical statistics method. It analyzes the changes of the students' infiltration moral education in experimental class and control class, and provides reference for the application and promotion of sports option moral education in teaching.

\section{RESULTS AND ANALYSIS}

\section{1. the data comparison of moral guidance of experimental class and control class}

The survey data show that: the basic skills of dragon dance of the students in the control class and the experimental class are almost zero, and there is no significant difference before the experiment. After the experiment, the importance of moral education in school education: $82.47 \%$ of the experimental class and $80.81 \%$ of the control class think it is very important, and there is no obvious change; In the aspect of infiltrating moral education, $31.96 \%$ and $35.35 \%$ of the experimental class and the control class thought it was obtained through the infiltration of each course, $26.80 \%$ and $34.34 \%$ thought it was obtained through the teaching of Ideological and political theory course; The comparison 
table of the two ways was significantly higher than that of the experimental class; $13.40 \%$ and $15.15 \%$ thought it was obtained through the infiltration of physical education curriculum. There was no significant difference between the control class and the experimental class; However, $14.43 \%$ and $6.06 \%$ of the students thought that they got it through thematic education guidance activities, and the experimental class was significantly higher than the control class (Table 1).

Table 1: Statistics of moral guidance of school moral education penetration to students $(\mathrm{n}=197)$

\begin{tabular}{lcc}
\hline \multicolumn{1}{c}{ Questionnaire content } & Experimental & control \\
The importance of moral education in school education & $82.47 \%$ & $80.81 \%$ \\
Moral education is obtained through the teaching of various courses & $31.96 \%$ & $35.35 \%$ \\
Moral education is obtained through the teaching of Ideological and political theory & $26.80 \%$ & $34.34 \%$ \\
Moral education is obtained through the teaching of physical education & $13.4 \%$ & $15.15 \%$ \\
Moral education is guided by theme education & $14.43 \%$ & $6.06 \%$ \\
\hline
\end{tabular}

\section{2. comparison of teaching methods between experimental class and control class}

According to the statistical results of the questionnaire, in the aspect of physical education classroom teaching, students think that the relationship between teachers and students is harmonious, and they can form good communication and interaction. There are $92.78 \%$ students in the experimental class and $90.91 \%$ students in the control class, and there is no significant difference; However, in terms of clear classroom routine and standardized teacher-student behavior: Although the proportion of the experimental class and the control class is small, there are still significant differences, which are $27.84 \%$ and $19.19 \%$ respectively, indicating that the experimental class has higher and higher requirements for students' behavior norms, In the aspect of infiltration effect of moral education in the teaching process: $72.16 \%$ and $70.71 \%$ of the students in the experimental class and the control class think that it is important for physical education teachers to establish a good image and demonstrate themselves. The theory and activities of physical education in classroom teaching are between $10 \%$ and $16 \%$ respectively. Only $1 \%$ of the students gave feedback. Obviously, the students in the experimental class and the control table think that teachers' demonstration is the best way to infiltrate moral education (Table 2).

Table 2: Statistics of the implementation of dragon dance elective course $(n=197)$

\begin{tabular}{llc}
\hline \multicolumn{1}{c}{ Questionnaire content } & Experimental & control \\
It is believed that the relationship between teachers and students is harmonious, and & $92.78 \%$ & $90.91 \%$ \\
good communication and interaction can be formed & & $19.19 \%$ \\
It is believed that there are clear classroom routines and teacher-student behavior & $27.84 \%$ & $70.71 \%$ \\
norms & $72.16 \%$ & $11.22 \%$ \\
It is beneficial to the cultivation of students' moral character for PE teachers to set up \\
a good image and demonstrate themselves & $10.31 \%$ & $16.49 \%$ \\
The influence of sports theory on Classroom Teaching & $16.33 \%$ & $1.02 \%$ \\
The influence of physical education on the implementation of classroom teaching & $1.03 \%$ & \\
The influence of implementing student evaluation feedback & &
\end{tabular}




\section{3. comparison of teaching contents of dragon dance optional course between experimental class and control class}

The survey data show that: Dragon Dance elective course infiltration of moral education effect: $72.16 \%$ and $79.80 \%$ of the students in the experimental class and the control class think that it can also improve ideological cultivation, regulate moral behavior, and establish national cultural self-confidence; However, $11.34 \%$ and $7.07 \%$ thought that they only need to learn motor skills in class; In the aspect of students' attitude towards the infiltration of moral education into dragon dance elective course: $70.1 \%$ of the students in the experimental class and $83.84 \%$ of the students in the control class think that it plays an important role in the cultivation of students' moral and psychological quality, so we should strengthen the infiltration of moral education; Obviously, the students in the control table have a strong desire to infiltrate moral education (Table $3)$.

Table 3: Statistics on the effect of moral education in Dragon Dance elective course $(\mathrm{n}=197)$

Questionnaire content

Students think that it can improve the ideological cultivation, standardize moral behavior, and establish national cultural confidence

Students think that they only need to learn motor skills in class

Recognition of moral education in Dragon Dance elective course
Experimental

control

$72.16 \%$

$79.80 \%$

$11.34 \%$

$7.07 \%$

$70.10 \%$

$83.84 \%$

\section{CONCLUSIONS AND SUGGESTIONS}

\subsection{The Dragon Dance elective course under the background of sports "Ideological and political course" is conducive to improving the teaching effect of moral education.}

At present, the students in Higher Vocational Colleges recognize the importance of moral education very much. In terms of access to moral education, it has developed from the single channel of Ideological and political theory teaching in the past to various disciplines. This study also finds that the theme education activities in 2020 are generally recognized by students. At the same time, we should also do a good job in the teaching reform and innovation of Ideological and political education, pay attention to the effect of moral education infiltration in each class, improve the times of moral education infiltration, and combine the characteristics of teaching content to avoid the uniformity of Ideological and political content.

\section{2. to improve teachers' sense of responsibility for moral education is conducive to stimulating the implementation effect of moral education infiltration teaching.}

With the promotion of the teaching reform of physical education in higher vocational colleges, students recognize the communication and interaction in the classroom and the moral education in the implementation of the curriculum, and students clearly think that a good teacher image and demonstration is the most effective way to infiltrate moral education, which is the so-called moral education as a teacher and a model[5]. Therefore, physical education teachers in higher vocational colleges not only need to improve their moral cultivation and set an example, but also need to combine the characteristics of optional courses to enrich the moral education teaching content. In the Dragon Dance elective course, every teacher should conscientiously implement the fundamental task of "establishing morality and cultivating people" put forward since the 18th National Congress of the Communist Party of China, and achieve the goal of educating people in the Dragon Dance elective course through the teaching concept of "cultivating people with sports, cultivating people with sports and cultivating people with sports"[6].

\section{3. enriching the content of moral education in Dragon Dance elective course is conducive to improving students' Ideological and moral and cultural cultivation.}

At present, the achievements of moral education in higher vocational colleges are gratifying. The reform of Ideological and political education in physical education has achieved good results. The overall moral quality of students is good, and the theme of students' moral cultivation is upward. At the same time, we can clearly sort out the common characteristics of the lack of students' moral education development. Students attach importance to professional skills and ignore the moral education of professional skills. Moral education is omni-directional and three-dimensional, so enriching the content of moral education is the top priority of the current physical education curriculum, but it cannot be mere formality. For example: during the anti epidemic 
period, every teacher cited the example of "Zhong Nanshan academician", which made the students feel like a mere formality. We should combine the characteristics of this course to carry out moral education.

\section{FUND PROJECTS}

2020 Shanghai Education Science Research General Project "Songjiang" Dragon Dance "sports elective course teaching practice research based on the inheritance of national intangible cultural heritage" (jy3-0200-20-02): 2020 Shanghai Vocational and Technical College of agriculture and forestry "party building leader" and "academic leader" project "practice research on moral education infiltration of dragon dance elective course in Higher Vocational Colleges" (jy2-0000-20-02 (21))

\section{REFERENCES}

[1] Outline of national education medium and long term reform and development plan (2010-2020). China government website, July 2010

[2] National vocational education reform implementation plan 2019 (referred to as vocational education 20). China government website, GF [2019]. No.4

[3] Wang puchen, the exploration of moral education infiltration of students in Higher Vocational Physical Education in Baotou City[D] Inner Mongolia Normal University, 2011

[4] Research on the infiltration of moral education in Primary School Physical Education Teaching -Based on the analysis of observing the physical education of primary school attached to Agricultural University. [D] Beijing Sport University

[5] Wu Yongmei. On the moral education function of Physical Education [J]. Sports science, 1998 (02): 15

[6] Zhou Fengxiang. Reflections on the effective infiltration of moral education in the process of physical education in primary and secondary schools $[\mathrm{J}]$. Sports science and technology literature bulletin,2014 (07) : 60+109. 